\title{
Involving Students in Educational Design: How Student Voices Contribute to Shaping Transdisciplinary CLIL History Materials
}

\author{
Silvia Bauer-Marschallinger, University of Vienna/KPH Vienna-Krems
}

silvia.bauer-marschallinger@univie.ac.at

\begin{abstract}
Although many studies have investigated students' perspectives towards Content and Language Integrated Learning (CLIL), few studies have actively involved learners when creating research-based materials. The scarcity of such studies also stems from the limited number of research projects that operationalize scientific insights for classroom implementation in the first place. This paper is connected to such a study, set within a design-based research (DBR) framework. Apart from investigating theoretical underpinnings of content and language integration, this ongoing $\mathrm{PhD}$ study also involves the development of research-based transdisciplinary content-and-language-integrative teaching materials over several cycles. Amongst other forms of data collection, focus group interviews with students before and after each intervention formed a central element of the design process. This work-in-progress article is concerned with the students' role in shaping content-and-language-integrative materials, shedding light on their concerns and needs at various stages in the design process. Initial results suggest that the learners' voices were crucial in the development of these materials. Moreover, in line with the overall thrust of DBR, it appears that a one-time intervention does not suffice even when considering the students' beliefs and needs. Instead, several cycles of development are needed to create an approach that works for the learners.
\end{abstract}

Keywords: CLIL, subject literacy, integrated pedagogy, design-based research, student voices

This work is licensed under the Creative Commons Attribution-ShareAlike 4.0 International agreement (CC BY-SA 4.0). http://creativecommons.org/licenses/by-sa/4.0/
Journal for the Psychology of Language Learning ISSN: 2642-7001. https://doi.org/10.52598/jpll/2/2/8 Volume 2, Issue 2, pp. 107-117

(Special Issue: The Psychology of Teaching and Learning Content \& Language) 
This work-in-progress article introduces an ongoing $\mathrm{PhD}$ project which (1) examines theoretical assumptions about the link between content and language learning and (2) operationalizes these insights for classroom implementation by developing research-based teaching materials for uppersecondary CLIL history education over several development cycles in collaboration with secondary teachers.

To provide an overview, the background and theoretical basis as well as the methodology of said PhD study are briefly outlined and discussed. Additionally, this short paper provides an insight into one aspect of the design process, namely how the students' voices, on an exemplary basis, contributed to shaping these materials. Here, the focus first lies on if or how these learners experienced the integration of content and language learning before the intervention and what kind of support measures they would need or wish for in this regard. Then, the students' response to our approach is examined, focusing on the linguistic support provided by the materials. Finally, implications of these results are discussed and, as an outlook, connected to the remaining data of the overarching project.

\section{LITERATURE REVIEW AND BACKGROUND}

\section{Integrating Subject-Specific and Language-Didactic Perspectives in CLIL}

For a long time, empirical research on CLIL ${ }^{1}$ either focused on its impact on language learning or, to a markedly lesser extent, on subject learning (see e.g., Fernández-Sanjurjo et al., 2017; San Isidro, 2019). The majority of these studies report a positive effect of CLIL on various aspects of language learning, including affective factors, and a neutral effect on content learning (Dalton-Puffer, 2008; San Isidro, 2019). Yet, in recent years, many outcome-oriented studies have been criticized for methodological issues such as inadequate matching of control groups (reflecting the selection bias often found in CLIL programs) or for missing or insufficient statistical analysis (Graham et al., 2018; Meyerhöffer \& Dreesmann, 2019), raising skepticism concerning the effectiveness of CLIL (Pérez Cañado, 2016a; San Isidro, 2019). Furthermore, results of studies examining subject-specific language performance tend to be less favorable, calling into question whether CLIL would reach its full potential (Meyer et al., 2015).

In light of these developments, CLIL researchers started to focus on the integration of content and language learning as the label would suggest. For instance, Nikula et al. (2016) dedicated an entire edited volume to the conceptualization of content and language integration. Meyer et al. (2015) argue that the interplay of content and language learning is inadequately understood and maintain that the integration of content and language is essential for learning. Many studies aiming at integrating subject and language perspectives work with notions set within a framework of Systemic Functional Linguistics (SFL), such as genres or subject literacies (e.g., Lo \& Jeong, 2018; McCabe \& Whittaker, 2017). Although very insightful, the results and pedagogical implications of SFL-based studies are deeply rooted in linguistics and thus might not be viable for many CLIL teachers, who often do not have a background in linguistics. Meyer et al. (2015) argue that most research on content and language integration has failed to translate into classroom practice or to lead to sufficient creation of appropriate material. Furthermore, this aspect tends to be insufficiently covered in teacher training programs (Pérez Cañado, 2016b).

\section{Operationalizing the Integration of Content and Language: Cognitive Discourse Functions}

One notion that presumes conceptual integration of subject and language pedagogies and also appears to be tangible for content teachers is the concept of Cognitive Discourse Functions (CDFs). Dalton-Puffer (2016) defines CDFs as "verbal routines that have arisen in answer to recurring demands while dealing with curricular content, knowledge items and abstract thought” (p. 29). Following the review of numerous previous models and taxonomies of academic language function, Dalton-Puffer (2013, 2016) identifies seven central CDF-Types, as shown in Table 1. 
Table 1. The CDF-Construct (Dalton-Puffer \& Bauer-Marschallinger, 2019, p. 35)

\begin{tabular}{|c|c|c|}
\hline Communicative Intention & Type & Examples of CDF verbs \\
\hline $\begin{array}{l}\text { I tell you how we can cut up the world } \\
\text { according to certain ideas }\end{array}$ & CATEGORIZE & $\begin{array}{l}\text { classify, compare, contrast, match, structure, } \\
\text { categorize, subsume }\end{array}$ \\
\hline $\begin{array}{l}\text { I tell you about the extension of this object of } \\
\text { specialist knowledge }\end{array}$ & DEFINE & define, identify, characterize \\
\hline $\begin{array}{l}\text { I tell you details of what I can see (also } \\
\text { metaphorically) }\end{array}$ & DESCRIBE & describe, explain, label, name, specify \\
\hline I tell you what my position is vis a vis $X$ & EVALUATE & $\begin{array}{l}\text { evaluate, judge, argue, justify, take a stance, } \\
\text { critique, comment, reflect }\end{array}$ \\
\hline $\begin{array}{l}\text { I give you reasons for and tell you about the } \\
\text { causes/ motives of } X \text {. }\end{array}$ & EXPLAIN & $\begin{array}{l}\text { explain, reason, express cause/effect, draw } \\
\text { conclusions, deduce }\end{array}$ \\
\hline $\begin{array}{l}\text { I tell you something that is potential (i.e. non- } \\
\text { factual) }\end{array}$ & EXPLORE & $\begin{array}{l}\text { explore, hypothesize, speculate, predict, guess, } \\
\text { estimate, simulate }\end{array}$ \\
\hline $\begin{array}{l}\text { I tell you sth. external to our immediate } \\
\text { context on which I have a legitimate } \\
\text { knowledge claim }\end{array}$ & REPORT & $\begin{array}{l}\text { report, inform, recount, narrate, present, } \\
\text { summarize, relate }\end{array}$ \\
\hline
\end{tabular}

As Table 1 illustrates, each prototypical type is based on a communicative intention central for dealing with content (left column) and could be elicited by a number of performative verbs (right column), reflecting action-related demands often present in content subject curricula. ${ }^{2}$ These types are neither disjunct nor mutually exclusive, creating somewhat fuzzy categories, which, according to DaltonPuffer (2013), would allow the accommodation of different (subject-) cultural models. This CDF-Construct has been empirically validated for different subjects in a number of MA-theses, summarized in Dalton-Puffer et al. (2018). Furthermore, Dalton-Puffer and Bauer-Marschallinger (2019) have shown that the CDF-Construct is compatible with competency-based history education as conceptualized in the Austrian context, both from a theoretical and empirical point of view, indicating that CDFs could work well to operationalize the integration of subject and language learning. Morton (2020), too, argues that CDFs can be used as "building blocks" to foster "focused and principled integration of content, literacy and language” (p. 11). Similarly, Nashaat Sobhy (2018), who looked into the operationalization of teaching definitions in the context of content-based instruction, concludes that Dalton-Puffer's CDF-Construct is "useful in the creation of a blueprint to teaching 'defining'” (p. 108) and recommends to explore CDFs more extensively to "conciliate teaching content and language” (p. 110). Along these lines, the aim of this $\mathrm{PhD}$ study is a research-based operationalization of the integration of content and language learning in the context of history with the help of CDFs. For this purpose, competency-based history materials were collaboratively developed. These materials scaffold input and output on the basis of CDFs by topicalizing underlying communicative intentions found in historical texts and sources, thereby working through the input in a guided way, as well as by helping learners express their cognitive operations via explicit linguistic support tied to the content presented. ${ }^{3}$

\section{Student Voices in CLIL}

While several studies have explored students' beliefs, perceptions, and attitudes regarding CLIL, usually reporting 
a positive relationship between CLIL and learner attitudes (Coyle, 2013; Pavón Vázquez, 2018; Somers \& Llinares, 2018) as well as general student satisfaction (Hüttner et al., 2013; Oxbrow, 2018), there seem to be hardly any studies that actively involved learners when creating researchbased CLIL materials (as in e.g., Banegas, 2013; Gupta, 2020). Yet, previous research suggests that learners indeed can effectively contribute to improving the quality of their education while also elucidating our understanding of their learning processes (Cook-Sather, 2006; Coyle, 2013; Flutter \& Rudduck, 2004). Coyle (2013), thus, calls for providing learners with more agency and for regarding them as "competent social actors" (p. 249) to make the learning process more successful. Döring (2020), who investigated the beliefs and perceptions of upper-secondary Austrian CLIL students, agrees and argues that involving students actively in the design and preparation process might be a key factor for successful CLIL. In this spirit, this paper considers the students' voices in order to create materials they can accept and perceive as beneficial for their learning processes. To be more precise, 'student voices', in this paper, include learners' perceptions and evaluations of a CDF-based approach to content and language integration. Moreover, it comprises the students' beliefs regarding how content and language can or should be integrated in CLIL with a view to their own learning needs.

\section{METHODOLOGY}

\section{Design-Based Research (DBR)}

For the purpose of creating research-based materials while also investigating the theoretical underpinnings of content and language integration, this research project adopted a DBR methodology. DBR is a relatively new methodological approach that is dual-focused and assumed to be capable of bridging theory and practice (Anderson \& Shattuck, 2012). In DBR studies, researchers and practitioners usually collaborate to develop pedagogical tools attending to local needs over multiple design cycles (McKenney \& Reeves, 2012). During such a process, rather than simply looking into "what works", the main emphasis lies on "how we can make something work and why" (McKenney \& Reeves, 2014, p. 143), thereby advancing theoretical foundations.

\section{Context of the Study}

This study is set in the context of two upper-secondary vocational high schools (focusing on business administration) in Vienna, Austria. In school A, students can enrol in a fully-fledged bilingual program, meaning that at least $50 \%$ of their content subjects are taught in English. In school B, students can opt for a so-called "CLIL-class" where 72 hours of CLIL are required across all subjects each year. ${ }^{4}$ At each school, one group at grade 11 (age 16-17) was involved in the main study. The materials for the main cycle were developed with each group's history teacher. $\mathrm{T}_{\mathrm{A}}$ (school A) teaches English and history while $\mathrm{T}_{\mathrm{B} 2}$ (School B) teaches history and geography. ${ }^{5}$

\section{Research Process}

The research process is visualized in Figure 1. After trying out instruments and first drafts of pedagogical materials during the pilot phase ${ }^{6}$, this study developed two units of pedagogical intervention over three cycles. The first unit, developed in cycle 1 (school A) and 2 (school B), focuses on Absolutism and Mercantilism, while cycle 3 tried to exploit previous insights for the creation of a new unit focusing on the Industrial Revolution (unit 2) in the context of school A.

Methodologically, each cycle followed a similar structure. At the beginning of a cycle, the needs of students and teachers were identified through (focus group) interviews, observations, and written tasks. In light of these insights, pedagogical interventions incorporating CDF theory were collaboratively produced by the researcher and teachers. The teachers then implemented these pedagogical tools in their respective classrooms (video-taped). As a next step, the process and product were formatively evaluated, using written student performances, retrospective interviews with teacher and students, and in the case of cycle 2 and 3, short feedback forms for students. In accordance with these results, the interventions were adapted and then re-implemented, followed by another evaluation process. After three rounds of intervention, the materials were finalized. ${ }^{7}$ 
Figure 1. Research Design

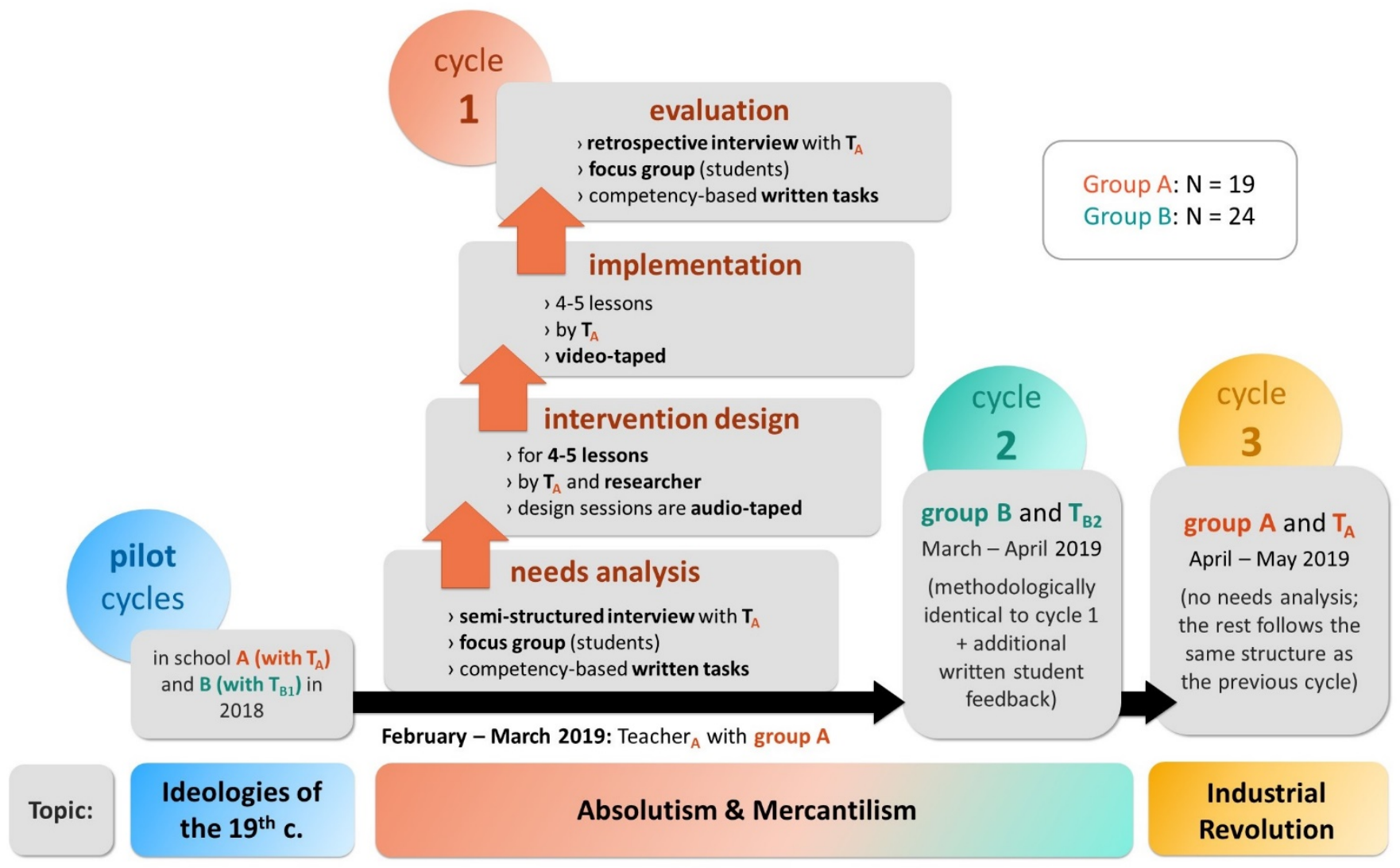

\section{Interview Data and Analysis}

As outlined above, students and teachers were interviewed several times using a semi-structured approach to document the participants' views throughout the project. Teachers were interviewed individually, whereas students were interviewed in groups of five to seven, reflecting different levels of ability and motivation, as viewed by the teacher (and, to a lesser extent, as indicated by the pre-intervention task performance). All interviews were transcribed, anonymized $^{8}$, and fed into MaxQDA 2020. To ensure continuous documentation of how the learners' views developed while maintaining representation of all proficiency levels, it was decided in cycle 2 and 3 to add the possibility of giving feedback in written form in case of student absences on the day of the interview, using brief feedback forms. Written feedback and interview transcripts were both analysed via qualitative content analysis (QDA) as specified by Kuckartz (2016), using a deductiveinductive approach. ${ }^{9}$

\section{RESULTS OF THE STUDENT INTERVIEWS}

\section{Context, Needs, and Wishes}

The two pre-intervention focus interviews revealed that neither group had experienced bilingual education that could be considered content-and-language-integrative. Group B, in fact, reported that they only experienced superficial bilingual teaching. For example, IMJ07 said that he did not really notice being in a CLIL strand as "the only thing that could happen would be the maths teacher entering the room saying 'Good morning' in English"10. Group B seemed dissatisfied with how CLIL was implemented and consequently were quite critical concerning the approach. Group A, in contrast, had experienced high levels of exposure to English as a language of instruction and seemed very positive towards English-medium content teaching. 
Despite their differing experiences and attitudes, the students reported similar learning needs, such as issues with vocabulary and archaic language often found in historical texts and text comprehension in general and would therefore welcome some support in these matters. Additionally, the learners said that they struggled with adequately responding to performative verbs often used in tasks and exams. The learners stated that they were not sure what certain performative verbs entailed and what teachers would expect. As a result, in testing situations they would often just reproduce what they remembered from class, hoping that the teacher "would pick the right things" (IKS12/A). In general, the students reported that they struggled with expressing themselves clearly in CLIL lessons, especially when dealing with challenging content:

If it's about history [...] I can talk fluently in German, but in English, I start stammering, I realized. But yeah, in that case, I just try to define something somehow. (IKS12/A)

IKS12's second sentence also indicates that her ideas of what certain academic language functions would encompass were imprecise as, from her perspective, everything would be "defin[ing] something somehow".

Another area where these learners only had a vague understanding relates to the integration of content and language. While the students seemed to perceive that content and language learning were connected somehow, they conceptualized this link mostly on the lexical level. For example, OPB05 (A) explained that "[y]ou have to know the words, otherwise you can't write it down or say it”. Consequently, when directly asked how language and content learning should be combined in classroom materials, they could think of nothing except glossaries.

\section{Reaction to the Intervention and Development of the Design}

Although the students of group A expressed satisfaction with the type of tasks and the general (scaffolded) approach, they, overall, reported their frustration. One main area they were dissatisfied with was the balance of content and language. For them, there was too much explicit focus on language, “making it feel like English class” (ETS12). Listening to their experiences and corroborating their views with the video-taped lessons, it appeared that the students were not unhappy with the materials per se, but rather, were frustrated with the strong focus on the linguistic support and the phraseboxes during whole-class discussion. OPB04, for instance, remembered that "even if your sentence was correct, you had to do it all over again because the phrases were not in there". Reported by students and visible in the transcripts, the teacher often asked for "a new phrase" rather than for new ideas and tended to comment the form instead of the message, which, based off the interview data and video-taped lessons, seems to have annoyed the students. Similarly, the students reportedly felt that the linguistic support was not specific enough for the subject history. Instead, they wished for language boxes that were tightly linked to subject matter.

These insights (among others) were considered when revising this unit for the students of group B. ${ }^{11}$ These students mostly responded positively to the materials and did not report the same problems as group A. Particularly, most of the high-achieving students reported that they were happy with the intervention, stating that they enjoyed the "tasks and variety" (UCQ07/ written feedback) or welcomed the "consistent use of English" and the "many tips and words one could use” (UKV05/ written feedback). Low- and mid-achievers also reported to appreciate the new approach in principle but felt somewhat overwhelmed by the increased use of English, the amount of writing, and the complex input. To some extent, the linguistic support was reported to help the learners cope with challenging materials. ICK01, for example, explained that "it got more and more complicated and at one point, the [...] box[es] didn't help anymore and from that moment onwards, I didn't really get it any longer”. For her, the linguistic support was necessary to process the content, but overall, the materials were too complex. On top of this, the interviewees felt that subjectspecific linguistic considerations were not useful to them and thus, in contrast to group A, stated that they preferred more general linguistic support.

The materials used in cycle 3 (school A) tried to incorporate and consolidate previous insights aiming for subject-specific language support as requested by group A students while also being more attuned to different proficiency levels within the group. The feedback of the students was overwhelmingly positive, arguing that this time, the linguistic support was "helpful and convenient" (EVS03), helping them to pay attention and express their ideas more easily. Even students who complained about the 
uselessness of the linguistic support after cycle 1, such as ETS12, now perceived the intervention as "less extreme" and the boxes as helpful.

\section{DISCUSSION AND IMPLICATIONS FOR THE DESIGN}

In summary, before the intervention, the students involved in this study reported that they had not experienced a form of bilingual education that approached content and language learning from an integrative angle. In the course of the interviews, however, both groups voiced the need for both input and output scaffolding to make historical content accessible to them. Considering that they also mentioned difficulties with expressing certain language functions and responding appropriately to performative verbs, which matches the results by Dalton-Puffer and BauerMarschallinger (2019), a CDF-based approach appeared to be suitable for the development of CLIL materials, which is in line with suggestions by Morton (2020) and Nashaat Sobhy (2018).

In the development process, the student interviews indicated a basic direction for the design by stating which general aspects of CLIL education these learners struggled with and which features they would like to see in the materials whereas the interviews with the teachers and the pre-intervention written performances identified more specific areas for the students to work on. Moreover, the students did not have any ideas how content and language could be integrated in classroom materials apart from clarifying vocabulary. This reflects their understanding of content and language integration, which seems limited to the lexical level, a finding echoed in the pilot study (BauerMarschallinger, 2019). This implies that only considering self-reported learner needs might not be enough when creating research-based materials that aim for content and language integration, but other sources such as teacher views or student performances should be taken into account, too (see Lo \& Jeong, 2018).

Turning to the students' reactions, it seems that only considering the students' initial wishes and needs would not ensure subsequent student approval of the materials. In other words, when creating an approach that is markedly different from their conventional lessons as is the case in this study, several development loops are needed to create materials accepted by the students, which is in keeping with DBR principles (see, e.g., McKenney \& Reeves, 2012). For this process, the students' feedback played an essential role, which is in agreement with Coyle's (2013) or Döring's (2020) call for viewing learners as competent agents capable of improving their own education. Listening to their voices allowed the material designers to fine-tune the nature of the support materials. In the case of group A, for example, the students' acceptance of the new approach increased considerably by considering their feedback and framing the linguistic support differently, i.e., explicitly highlighting how certain linguistic aspects relate to the language of history and the content presented. This first postintervention interview also has shown that dealing with these linguistic aspects more subtly and during elaboration phases $^{12}$ would be central for student satisfaction. This insight was then incorporated into the teacher's version.

Student approval of the materials, in turn, ensured that learners did not reject or ignore the additional tips and boxes, ultimately improving learning outcomes, both as perceived by students and teachers and as measured on the basis of their written task performances throughout the project. Group A's results of the written tasks improved slightly from pre- to first post-intervention task before increasing more substantially from first to second post-intervention task $^{13}$, somewhat mirroring the tone of the respective postintervention interview. Group B, on the other hand, only improved in terms of language ${ }^{14}$ while content results virtually did not change at all. Here, another cycle considering their wishes and needs, such as a lower difficulty level - or ideally offering a variety of levels - as well as more general language support, might have resulted in better results both in terms of language and content.

Concerning the type of linguistic support measures, the two groups differed in their views. After the first intervention, group A called for subject-specific language boxes, whereas group $\mathrm{B}$ preferred more general language boxes. This difference in preference might be explained by their difference of programs. Group A reported a high level of exposure to English and might therefore be bored with 'general' language support while group B might not have had the same foundations. Again, it seems crucial to consider the students' needs and listening to their feedback at various stages and more than once to attune materials. As mentioned before, in the pre-intervention interviews, the type of linguistic support could not be discussed, in actuality, 
as these learners simply could not imagine what this could look like in the subject of history. Only after the intervention, they could express their thoughts and needs in an informed way. Overall, it seems that learners appreciated the opportunity to help shape new didactic materials and once their views could be sufficiently incorporated, they also valued the CDF-based approach to content and language integration.

${ }^{1}$ Abbreviation for Content and Language Integrated Learning, which refers to "a dual-focused educational approach in which an additional language is used for the learning and teaching of both content and language” (Coyle et al., 2010, p. 1).

${ }^{2}$ For a full representation and discussion of the construct, see DaltonPuffer (2013, 2016).

3 For more information on the operationalization of the CDFConstruct for the design of history materials, see BauerMarschallinger (in preparation). Some illustrative examples can also be found in Bauer-Marschallinger (2019).

${ }^{4}$ An obligatory minimum of 72 lessons of CLIL per year is now anchored in the curriculum of this school type (see Austrian Federal Ministry for Education [2014]).

${ }^{5}$ In Austria, with some exceptions, teachers are qualified in two subjects.

${ }^{6}$ See Bauer-Marschallinger (2019) for more information and results of the pilot study.

7 Some examples of the pilot materials are available in BauerMarschallinger (2019). The materials of the main study will be published in Bauer-Marschallinger (in preparation).

\section{CONCLUSION}

This short article provides just a glimpse into the collaborative development of CDF-based materials as only certain features were discussed. Furthermore, these results were presented in a somewhat isolated way, only hinting at links to other parts of the study, which does not adequately represent the complexities of the design process. Still, this paper has shown that the students' feedback was vital to create content-and-language-integrative materials the learners could readily accept and even appreciate, ultimately resulting in better learning outcomes.

\footnotetext{
${ }^{8}$ For the purpose of anonymization while also tracking the students' development, students created their own codes, consisting of certain letters of their and their caretakers first name as well as the learner's birth month. This way, the students would be able to reconstruct their own code in case they forgot them, without serious risk of identification.

${ }^{9}$ This article focuses on the student interviews. For more information on the analysis of other data types, see Bauer-Marschallinger (2019) and (in preparation) or contact the author directly.

10 All interviews were conducted in German to ensure that participants could express themselves freely. The extracts presented were translated by the author.

11 These changes, including the rationales behind didactic decisions, are outlined in detail in Bauer-Marschallinger (in preparation).

12 i.e., individual or group work.

13 These changes were statistically significant as measured by ANOVA with repeated measures and Friedman tests (where data was not normally distributed).

${ }^{14}$ These changes were statistically significant as measured by t-tests.
}

\section{Notes on the author}

Silvia Bauer-Marschallinger is PhD student in the English Department at the University of Vienna. Before being awarded a fellowship for the doctoral project outlined in this article, she taught English and history (bilingually) at two upper-secondary vocational schools. As of October 2020 she joined the KPH Vienna/Krems as a lecturer in English Language Teaching. 


\section{REFERENCES}

Anderson, T., \& Shattuck, J. (2012). Design-based research: A decade of progress in education research? Educational Researcher, 41(1), 16-25. https://doi.org/10.3102/0013189X11428813

Austrian Federal Ministry for Education. (2014). Curriculum for the Secondary College for Business Administration. Austrian Federal Ministry for Education. BGBl. https://www.hak.cc/node/4336

Banegas, D. L. (2013). Teachers developing languagedriven CLIL through collaborative action research in Argentina [Doctoral dissertation, The University of Warwick]. University of Warwick. http://webcat.warwick.ac.uk/record=b2684752 S1

Bauer-Marschallinger, S. (2019). With united forces: How design-based research can link theory and practice in the transdisciplinary sphere of CLIL. CLIL. Journal of Innovation and Research in Plurilingual and Pluricultural Education, 2(2), 723. https://doi.org/10.5565/rev/clil.19

Bauer-Marschallinger, S. (in preparation). CLIL with a capital I - Using cognitive discourse functions to integrate language and content acquisition in the CLIL history classroom [Doctoral dissertation, University of Vienna].

Cook-Sather, A. (2006). Sound, presence, and power: "Student voice" in educational research and reform. Curriculum Inquiry, 36(4), 359-390. https://doi.org/10.1111/j.1467-873X.2006.00363.x

Coyle, D. (2013). Listening to learners: An investigation into 'successful learning' across CLIL contexts. International Journal of Bilingual Education and Bilingualism, 16(3), 244-266. https://doi.org/10.1080/13670050.2013.777384

Coyle, D., Hood, P., \& Marsh, D. (2010). CLIL: Content and language integrated learning. Cambridge University Press.

Dalton-Puffer, C. (2008). Outcomes and processes in content and language integrated learning (CLIL): current research from Europe. In W. Delanoy (Ed.), Anglistische Forschungen: Vol. 388. Future perspectives for English language teaching (pp. 139-157). Winter.

Dalton-Puffer, C. (2013). A construct of cognitive discourse functions for conceptualising contentlanguage integration in CLIL and multilingual education. European Journal of Applied Linguistics, 1(2), 99. https://doi.org/10.1515/eujal2013-0011

Dalton-Puffer, C. (2016). Cognitive discourse functions: specifying and integrative interdisciplinary construct. In T. Nikula, E. Dafouz, P. Moore, \& U. Smit (Eds.), Bilingual education and bilingualism: Conceptualising integration in CLIL and multilingual education (pp. 29-54). Multilingual Matters.

Dalton-Puffer, C., Bauer-Marschallinger, S., BrücklMackey, K., Hofmann, V., Hopf, J., Kröss, L., \& Lechner, L. (2018). Cognitive discourse functions in Austrian CLIL lessons: Towards an empirical validation of the CDF construct. European Journal of Applied Linguistics, 6(1), 5-29. https://doi.org/10.1515/eujal-2017-0028

Dalton-Puffer, C., \& Bauer-Marschallinger, S. (2019). Cognitive discourse functions meet historical competences: Towards an integrated pedagogy in CLIL history education. Journal of Immersion and Content-Based Language Education, 7(1), 30-60. https://doi.org/10.1075/jicb.17017.dal

Döring, V. (2020). Student voices on CLIL. Suggestions for improving compulsory CLIL education in Austrian technical colleges (HTL). CELT Matters, 4, 1-11. https://anglistik.univie.ac.at/staff/teamsand-research-groups/eduling/celtmatters/contributions/

Fernández-Sanjurjo, J., Fernández-Costales, A., \& Arias Blanco, J. M. (2017). Analysing students' contentlearning in science in CLIL vs. non-CLIL programmes: Empirical evidence from Spain. International Journal of Bilingual Education and Bilingualism, 1(1), 1-14. https://doi.org/10.1080/13670050.2017.1294142

Flutter, J., \& Rudduck, J. (2004). Consulting pupils: What's in it for schools? Routledge. 
http://site.ebrary.com/lib/alltitles/docDetail.action? docID=10101275

Graham, K., Choi, Y., Davoodi, A., Razmeh, S., \& Dixon, L. Q. (2018). Language and content outcomes of CLIL and EMI: A systematic review. Latin American Journal of Content and Language Integrated Learning, 11(1), 19-37. https://doi.org/10.5294/laclil.2018.11.1.2

Gupta, K. C.-L. (2020). Researcher-teacher collaboration in adopting critical content and language integrated learning (CLIL): Processes, challenges, and outcomes. Trabalhos Em Linguística Aplicada, 59(1), 42-77. https://doi.org/10.1590/010318136014125912020

Hüttner, J., Dalton-Puffer, C., \& Smit, U. (2013). The power of beliefs: Lay theories and their influence on the implementation of CLIL programmes. International Journal of Bilingual Education and Bilingualism, 16(3), 267-284. https://doi.org/10.1080/13670050.2013.777385

Kuckartz, U. (2016). Qualitative Inhaltsanalyse: Methoden, Praxis, Computerunterstützung (3rd revised edition). Grundlagentexte Methoden. Beltz Juventa.

Lo, Y. Y., \& Jeong, H. (2018). Impact of genre-based pedagogy on students' academic literacy development in Content and Language Integrated Learning (CLIL). Linguistics and Education, 47, 36-46.

https://doi.org/10.1016/j.linged.2018.08.001

McCabe, A., \& Whittaker, R. (2017). Genre and appraisal in CLIL history texts: Developing the voice of the historian. In A. Llinares, \& T. Morton (Eds.), Language Learning \& Language Teaching: volume 47. Applied linguistics perspectives on CLIL (pp. 105-124). John Benjamins Publishing Company. https://doi.org/10.1075/1llt.47.07mcc

McKenney, S. E., \& Reeves, T. C. (2012). Conducting educational design research. Routledge. https://doi.org/10.4324/9780203818183

McKenney, S. E., \& Reeves, T. C. (2014). Methods of evaluation and reflection in design research. In D. Euler, \& P. F. E. Sloane (Eds.), Zeitschrift für Journal for the Psychology of Language Learning
Berufs- und Wirtschaftspädagogik Beiheft. Design-based research (pp. 141-155). Franz Steiner Verlag.

Meyer, O., Coyle, D., Halbach, A., Schuck, K., \& Ting, T. (2015). A pluriliteracies approach to content and language integrated learning - mapping learner progressions in knowledge construction and meaning-making. Language, Culture and Curriculum, 28(1), 41-57. https://doi.org/10.1080/07908318.2014.1000924

Meyerhöffer, N., \& Dreesmann, D. C. (2019). Englishbilingual biology for standard classes development, implementation and evaluation of an English-bilingual teaching unit in standard German high school classes. International Journal of Science Education, 41(10), 1366-1386. https://doi.org/10.1080/09500693.2019.1607620

Morton, T. (2020). Cognitive discourse functions: A bridge between content, literacy and Language for Teaching and Assessment in CLIL. CLIL. Journal of Innovation and Research in Plurilingual and Pluricultural Education, 3(1), 7-17. https://doi.org/10.5565/rev/clil.33

Nashaat Sobhy, N. (2018). Operationalizing "defining” from a cognitive discourse perspective for learners' use. In S. Anwaruddin (Ed.), Knowledge Mobilization in TESOL (pp. 94-112). Koninklijke Brill NV. https://doi.org/10.1163/9789004392472_007

Nikula, T., Dafouz, E., Moore, P., \& Smit, U. (Eds.). (2016). Bilingual education and bilingualism: Conceptualising integration in CLIL and multilingual education. Multilingual Matters.

Oxbrow, G. L. (2018). Students’ perspectives on CLIL programme development: A quantitative analysis. Porta Linguarum, 29, 137-158.

Pavón Vázquez, V. (2018). Innovations and challenges in CLIL research: Exploring the development of subject-specific literacies. Theory into Practice, 57(3), 204-211.

https://doi.org/10.1080/00405841.2018.1484035

Pérez Cañado, M. L. (2016a). From the CLIL craze to the CLIL conundrum: Addressing the current CLIL ISSN 2642-7001. https://www.jpll.org/ 
controversy. Bellaterra Journal of Teaching \& Learning Language \& Literature, 9(1), 9-31. https://doi.org/10.5565/rev/jtl3.667

Pérez Cañado, M. L. (2016b). Are teachers ready for CLIL? Evidence from a European study. European Journal of Teacher Education, 39(2), 202-221.

https://doi.org/10.1080/02619768.2016.1138104
San Isidro, X. (2019). The multi-faceted effects of CLIL: A literature review. Nexus, 1, 33-49.

Somers, T., \& Llinares, A. (2018). Students' motivation for content and language integrated learning and the role of programme intensity. International Journal of Bilingual Education and Bilingualism, 1(4), 1-16.

https://doi.org/10.1080/13670050.2018.1517722 